\title{
Normalizing a hyperactive mTOR initiates muscle growth during obesity
}

\author{
David L. Williamson and Joshua C. Drake \\ Department of Exercise and Nutrition Sciences, School of Public Health, University at Buffalo, Buffalo, NY 14214, \\ USA
}

Received: 2/25/11; Accepted: 2/27/11; Published: 2/28/11

Corresponding author: David L. Williamson, PhD; Email: davidwil@buffalo.edu

(C) Williamson et al. This is an open-access article distributed under the terms of the Creative Commons Attribution License, which permits unrestricted use, distribution, and reproduction in any medium, provided the original author and source are credited.

Functional impairment is a major concern in the obese population, leading to reductions in everyday activities [1]. Obesity-related reductions in muscle function are due to a loss of muscle mass (i.e. sarcopenia), which occurs largely from an imbalance between the rates of protein synthesis and degradation [2,3]. A major controlling mechanism for muscle peptide/protein formation is messenger RNA (mRNA) translation. Initiation of translation is regulated by hormones and the diet through alterations in the mammalian Target of Rapamycin (mTOR) $[4,5,6]$. Despite hyperactivation of the growth-promoting, nutrient-sensing mTOR pathway, atrophy persists in obese muscle [7]. Chronic hyperactivation of mTOR signaling is atypical outside of disease states, such as obesity, dyslipidemia, hypercholesterolemia, or certain types of cancer. With the obesity rate growing at an alarming rate, there is a critical need to determine how obesity-related sarcopenia can be limited, since metabolic homeostasis is positively linked to muscle mass.

Given the hyperactive state of mTOR signaling in obese skeletal muscle, normalizing mTOR signaling (to levels observed in lean mice) may be one avenue of limiting the resultant sarcopenia. However, treatment of obese rodent models with the mTOR inhibitor, rapamycin, showed limited improvement in insulin sensitivity, despite reductions in adiposity [8]. Although, recent studies show that aged [9] and cancer prone [10] mice can withstand chronic rapamycin treatment. This suggests that the efficacy of chronic rapamycin treatment may rely upon the dose, delivery method, tissue-specific effects, and length of treatment. This issue requires more work. Likewise, the use of insulin sensitizers and/or AMP-activated protein kinase (AMPK)-agonists [11] has proven beneficial in improving obesity-related metabolic complications in skeletal muscle. AMPK is a well-characterized sensor of the cell's energy status [12]. Compounds like AICAR (an AMP mimetic) and metformin, lead to the activation and phosphorylation of AMPK. AMPK activation promotes enhanced expression of skeletal muscle oxidative-related enzymes, proteins, and metabolism, which are consistent with the findings that obese skeletal muscles are less oxidative and have lower AMPK activation (during fasted conditions). At the same time, AMPK activation also inhibits mTOR signaling $[13,14]$. However, it seems counterintuitive to inhibit an important growth-mediated pathway (i.e. mTOR), regulating muscle mass, so that skeletal muscles can grow.

Our recent data [15] show that short-term (2-week), daily treatment of obese $(\mathrm{ob} / \mathrm{ob})$ mice with AICAR normalized their hyperactive, fasted-state mTOR signaling. Along with the expected reductions in circulating blood glucose and insulin concentrations, and muscle lipid and glycogen content after AICAR treatment, translational capacity and mass (including muscle fiber areas) of the plantar flexor muscle complex were significantly increased in the obese treated mice. It is our view that the oxidative metabolism/capacity of the muscle and the regulatory processes of muscle growth (i.e. mTOR and translational control) need to be normalized to elicit growth in insulin resistant (e.g. obese, aged) muscle. There are emerging data $[16,17,18,19,20]$ that support our contention. Thus, gaining control of these initial signals and processes in 
obese, insulin resistant, and/or aging skeletal muscle with mTOR antagonists (e.g. rapamycin, metformin), may be beneficial to limiting sarcopenia and sarcopenia-related dysfunction.

\section{REFERENCES}

1. Stenholm S, Harris TB, Rantanen T, Visser M, Kritchevsky $S B$, et al. Sarcopenic obesity: definition, cause and consequences. Curr Opin Clin Nutr Metab Care. 2008; 11:693-700.

2. Durschlag RP, Layman DK. Skeletal muscle growth in lean and obese Zucker rats. Growth 1983. 47:282-291.

3. Kemp JG, Blazev R, Stephenson DG, Stephenson GM. Morphological and biochemical alterations of skeletal muscles from the genetically obese (ob/ob) mouse. Int J Obes (Lond). 2009; 33:831-841.

4. Beretta L, Gingras AC, Svitkin YV, Hall MN, Sonenberg N. Rapamycin blocks the phosphorylation of $4 \mathrm{E}-\mathrm{BP} 1$ and inhibits cap-dependent initiation of translation. EMBO J. 1996; 15:658-664.

5. Merrick WC, Hershey JWB. The pathway and mechanism of eukaryotic protein synthesis. In: Hershey JWB, Mathews $\mathrm{MB}$, Sonenberg N, editors. Translational Control. Cold Spring Harbor: Cold Spring Harbor Laboratory Press. 1996; 31-69.

6. Holz MK, Ballif BA, Gygi SP, Blenis J. mTOR and S6K1 mediate assembly of the translation preinitiation complex through dynamic protein interchange and ordered phosphorylation events. Cell. 2005; 123:569-580.

7. Um SH, Frigerio F, Watanabe M, Picard F, Joaquin M, et al. Absence of S6K1 protects against age- and diet-induced obesity while enhancing insulin sensitivity. Nature. 2004; 431:200-205.

8. Miller AM, Brestoff JR, Phelps CB, Berk EZ, Reynolds TH. Rapamycin does not improve insulin sensitivity despite elevated mammalian target of rapamycin complex 1 activity in muscles of ob/ob mice. Am J Physiol Regul Integr Comp Physiol. 2008; 295:R1431-1438.

9. Harrison DE, Strong R, Sharp ZD, Nelson JF, Astle CM, et al. Rapamycin fed late in life extends lifespan in genetically heterogeneous mice. Nature. 2009; 460:392-395.

10. Anisimov VN, Zabezhinski MA, Popovich IG, Piskunova TS, Semenchenko AV, et al. Rapamycin extends maximal lifespan in cancer-prone mice. Am J Pathol. 2010; 176:20922097.

11. Iglesias MA, Ye JM, Frangioudakis G, Saha AK, Tomas E, et al. AICAR administration causes an apparent enhancement of muscle and liver insulin action in insulin-resistant high-fatfed rats. Diabetes. 2002; 51:2886-2894.

12. Hardie DG. Minireview: the AMP-activated protein kinase cascade: the key sensor of cellular energy status. Endocrinology. 2003. 144:5179-5183.

13. Bolster DR, Crozier SJ, Kimball SR, Jefferson LS. AMPactivated protein kinase suppresses protein synthesis in rat skeletal muscle through down-regulated mammalian target of rapamycin (mTOR) signaling. J Biol Chem. 2002; 277:23977-23980.
14. Inoki K, Zhu T, Guan KL. TSC2 mediates cellular energy response to control cell growth and survival. Cell. 2003; 115:577-590.

15. Drake JC, Alway SE, Hollander JM, Williamson DL. AICAR treatment for 14 days normalizes obesity-induced dysregulation of TORC1 signaling and translational capacity in fasted skeletal muscle. Am J Physiol Regul Integr Comp Physiol. 2010; 299:R1546-1554.

16. Saha $A K, X u X J$, Lawson $E$, Deoliveira R, Brandon $A E$, et al. Downregulation of AMPK accompanies leucine- and glucose-induced increases in protein synthesis and insulin resistance in rat skeletal muscle. Diabetes. 2010; 59:24262434.

17. Harber MP, Konopka AR, Douglass MD, Minchev K, Kamisky LA, et al. Aerobic Exercise Training Improves Whole Muscle and Single Myofiber Size and Function in Older Women. Am J Physiol Regul Integr Comp Physiol. 2010; 297:R1452-1459.

18. Sengupta S, Peterson TR, Laplante M, Oh S, Sabatini DM. mTORC1 controls fasting-induced ketogenesis and its modulation by ageing. Nature. 2010; 468:1100-1104.

19. Blagosklonny MV. Rapamycin and quasi-programmed aging: Four years later. Cell Cycle. 2010; 9:1859-1862.

20. Selman C, Tullet JM, Wieser D, Irvine E, Lingard SJ, et al. Ribosomal protein S6 kinase 1 signaling regulates mammalian life span. Science. 2009; 326:140-144. 